\title{
Status and Perspectives on the Cosmic-Ray Neutron Method for Soil Moisture Estimation and Other Environmental Science Applications
}

Andreasen, Mie; Jensen, Karsten Høgh; Desilets, Darin; Franz, Trenton E.; Zreda, Marek; Bogena, Heye R.; Zibar, Majken Caroline Looms

Published in:

Vadose Zone Journal

DOI:

10.2136/vzj2017.04.0086

Publication date:

2017

Document version

Publisher's PDF, also known as Version of record

Document license:

CC BY-NC-ND

Citation for published version (APA):

Andreasen, M., Jensen, K. H., Desilets, D., Franz, T. E., Zreda, M., Bogena, H. R., \& Zibar, M. C. L. (2017). Status and Perspectives on the Cosmic-Ray Neutron Method for Soil Moisture Estimation and Other Environmental Science Applications. Vadose Zone Journal, 16(8). https://doi.org/10.2136/vzj2017.04.0086 


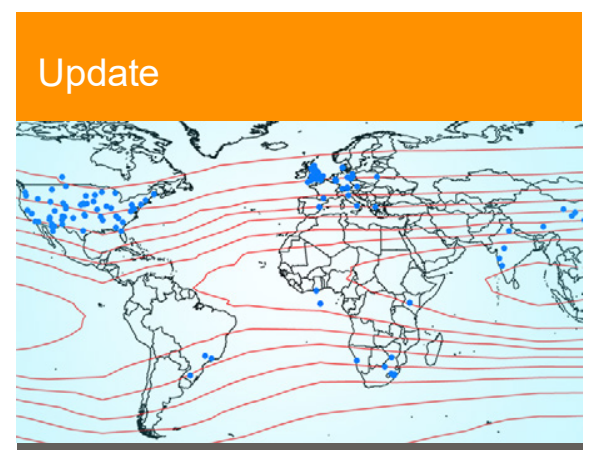

Core Ideas

- Numerous studies have been conducted to develop and examine the accuracy of the method.

- Cosmic-ray neutron soil moisture estimates compare well with independent measurements.

- These estimates are useful for

modeling, data assimilation, and calibration of satellite products.

- Many studies have used the neutron detector for other applications; results have been promising.

M. Andreasen, K.H. Jensen, and M.C. Looms, Dep. of Geosciences and Natural Resource Management, Univ. of Copenhagen, 1350 Copenhagen K, Denmark; D. Desilets, Hydroinnova LLC, Albuquerque, NM 87106; T.E. Franz, School of Natural Resources, Univ. of Nebraska, Lincoln, NE 68583; M. Zreda, Dep. of Hydrology and Water Resources, Univ. of Arizona, Tucson, AZ 85721; H.R. Bogena, Agrosphere IBG3, Forschungszentrum Jülich $\mathrm{GmbH}$, Jülich, Germany. *Corresponding author (mie.andreasen@ign.ku.dk).

Received 27 Apr. 2017.

Accepted 30 June 2017.

Citation: M. Andreasen, K.H. Jensen, D. Desilets, T.E. Franz, M. Zreda, H.R. Bogena, and M.C. Looms. 2017. Status and perspectives on the cosmic-ray neutron method for soil moisture estimation and other environmental science applications. Vadose Zone J. 16(8). doi:10.2136/vzj2017.04.0086

Vol. 16, Iss. 8, 2017

(c) Soil Science Society of America.

This is an open access article distributed

under the CC BY-NC-ND license

(http://creativecommons.org/licenses/

by-nc-nd/4.0/).

\section{Status and Perspectives on the Cosmic-Ray Neutron Method for Soil Moisture Estimation and Other Environmental Science Applications}

\author{
Mie Andreasen,* Karsten H. Jensen, Darin Desilets, \\ Trenton E. Franz, Marek Zreda, Heye R. Bogena, and \\ Majken C. Looms
}

Since the introduction of the cosmic-ray neutron method for soil moisture estimation, numerous studies have been conducted to test and advance the accuracy of the method. Almost 200 stationary neutron detector systems have been installed worldwide, and roving systems have also started to gain ground. The intensity of low-energy neutrons produced by cosmic rays, measured above the ground surface, is sensitive to soil moisture in the upper decimeters of the ground within a radius of hectometers. The method has been proven suitable for estimating soil moisture for a wide range of land covers and soil types and has been used for hydrological modeling, data assimilation, and calibration and validation of satellite products. The method is challenged by the effect on neutron intensity of other hydrogen pools such as vegetation, canopy interception, and snow. Identifying the signal of the different pools can be used to improve the cosmic-ray neutron soil moisture method as well as extend the application to, e.g., biomass and canopy interception surveying. More fundamental research is required for advancement of the method to include more energy ranges and consider multiple height levels.

Abbreviations: CRN, cosmic-ray neutron; MCNPX, Monte Carlo N-Particle Extended; SWE, snow water equivalent; URANOS, Ultra Rapid Adaptable Neutron-Only Simulation.

This update is an overview of the cosmic-ray neutron research conducted within environmental science. It includes the development of calibration functions for soil moisture estimation, correction factors, and footprint analyses. Research conducted to expand the application of the method is described along with the applicability of the soil moisture estimates. Finally, we include the challenges and potentials of cosmic-ray neutron detection.

Soil moisture controls the exchange of energy and water between the atmosphere and the land surface. Accurate and precise measurements of soil moisture are therefore essential for quantifying important processes like evapotranspiration, groundwater recharge, and overland flow (Vereecken et al., 2008). The cosmic-ray neutron (CRN) method for measuring soil moisture is based on background cosmic radiation and exploits the inverse relationship between H content and CRN intensity (Fermi, 1965; Bethe et al., 1940; Hendrick and Edge, 1966). Kodama et al. (1985) conducted the first CRN measurements for soil moisture estimation. They found the highest sensitivity to soil moisture changes using a neutron detector installed at $40 \mathrm{~cm}$ below the surface. However, the footprint of the buried neutron detectors was $<1 \mathrm{~m}^{2}$, whereas it increased substantially when the neutron detector was installed above the ground surface (Zreda et al., 2012). Zreda et al. (2008) found that aboveground CRN intensity is highly sensitive to soil moisture changes in the upper decimeters of the ground within a radius of hundreds of meters.

Due to the noninvasive character of the neutron intensity measurement technique, roving applications for regional applications of the CRN method are also possible. Because 
the CRN method provides soil moisture at a scale between the common point scale (e.g., electromagnetic sensors) and large-scale measurement methods (e.g., satellite sensing) (Zreda et al., 2012; Bogena et al., 2015), CRN soil moisture estimates are useful for various studies of land-surface processes. For instance, the measurement scale of the CRN method is similar to catchment-scale models with a horizontal discretization of hundreds of meters, the eddy covariance system used for actual evapotranspiration determination, and irrigation management systems such as, e.g., the center-pivot system. Although for most terrestrial field sites soil moisture is the most important pool of $\mathrm{H}$, many other $\mathrm{H}$ pools affect the neutron intensity, most notably the vegetation biomass (e.g., Zreda et al., 2012; Franz et al., 2013c), snow cover (Kodama et al., 1979; Kodama, 1980; Desilets et al., 2010; Zreda et al., 2012), canopy interception (Baroni and Oswald, 2015; Andreasen et al., 2017), and anthropogenic objects such as roads and buildings (Table 1).

The aim of this update is to provide an overview of the research on hydrological applications of cosmic-ray neutron physics and to discuss the challenges and potentials for the advancement and additional applications of the CRN method.

\section{Status of the Method}

\section{Cosmogenic Neutrons}

Primary cosmic-ray particles (mainly protons) travel toward the Earth at a rate varying according to the 11-yr solar activity cycle. The shielding of cosmic-ray particles, provided by the geomagnetic field, is described by the cutoff rigidity and is defined as "the minimum momentum per unit charge that an incident particle can have and still reach a given location above the earth" (Goldhagen et al., 2004). The cutoff rigidity is greatest at the geomagnetic equator and smallest at high latitudes (see Fig. 1). In the atmosphere,

Table 1. The H pools affecting the cosmic-ray neutron signal, as well as their dynamics (from Andreasen et al., 2017).

\begin{tabular}{|c|c|c|c|}
\hline Medium & $\begin{array}{l}\text { Static, } \\
\text { yearly }\end{array}$ & $\begin{array}{l}\text { Quasi-static, } \\
\text { sub-yearly }\end{array}$ & $\begin{array}{l}\text { Dynamic, } \\
\text { daily }\end{array}$ \\
\hline Soil moisture & & & $x$ \\
\hline Tree roots & & $x$ & \\
\hline Soil organic matter & & $x$ & \\
\hline Water in soil minerals & $x$ & & \\
\hline Vegetation (cellulose, water) & & $x$ & $x$ \\
\hline Snow & & $x$ & $\times$ \\
\hline Puddles & & & $\times$ \\
\hline Open water (river, sea, lake) & & $x$ & \\
\hline Canopy intercepted water & & & $\times$ \\
\hline Buildings and roads & $x$ & & \\
\hline Atmospheric water vapor & & & $x$ \\
\hline
\end{tabular}

primary cosmic-ray particles hit and disintegrate the nuclei of atmospheric gases, creating cascades of secondary neutrons. The cosmic-ray particles are attenuated as they interact with nuclei in the Earth's atmosphere, and the number of interactions and the intensity of cosmic-ray particles decrease with increasing atmospheric depth (the mass thickness per unit area) (Simpson, 1951; Zreda, 2016). High-energy neutrons (>10 MeV; see Fig. 2) colliding with nuclei produce fast (evaporation) neutrons (on the order of $1 \mathrm{MeV})$. The fast neutrons are moderated to epithermal $(>1 \mathrm{eV})$ and thermal neutrons $(<1 \mathrm{eV})$ as they travel and interact with the elements of the air, vegetation, and soil (Zreda et al., 2012; Köhli et al., 2015).

The probability of neutrons interacting with an atomic nucleus is described by an element's cross-section. Hydrogen is by far the most important element for the moderation (loss of energy) of epithermal neutrons as both the cross-section and the energy loss per collision is relatively high. In addition, the amount of $\mathrm{H}$ in soils is much higher than other elements with similar characteristics, e.g., B or $\mathrm{Gd}$. A change in the $\mathrm{H}$ content of the soil is immediately reflected in the measured ground-level epithermal neutron intensity due to the instantaneous mixing of neutrons in the atmosphere. The CRN method is based on low-energy neutrons produced by cosmic rays, and so far, most research has focused on epithermal neutrons because these are more sensitive to $\mathrm{H}$. The different sensitivity and different physical response of thermal and epithermal neutrons to $\mathrm{H}$ is obvious both at ground level (Fig. 2) and in the first hundreds of meters of air above the ground surface (Fig. 3). From the ground level, the thermal neutron intensity decreases with height (Fig. 3A). The moderation of epithermal neutrons (to thermal energies) is high in the soil and low in the air, and the decrease of thermal neutron intensity with height reflects the distance to the soil (i.e., the source of thermal neutrons). At some height above the ground (hundreds of meters to $1 \mathrm{~km}$ ), this boundary effect disappears and the thermal neutron intensity increases with height (data not shown) following the pattern of higher energy neutrons (e.g., epithermal neutrons; see Fig. 3B).

\section{Theoretical Development}

The theoretical basis of the CRN method was established using the neutron transport model Monte Carlo N-Particle Extended (MCNPX) radiation transport code (Pelowitz, 2011) and generic conceptualizations. The model was used to determine (i) the sensitivity of neutron intensity to soil moisture and snow (Zreda et al., 2008; Zweck et al., 2013; Desilets, 2017), (ii) the atmospheric water vapor correction model presented below (Rosolem et al., 2013), (iii) the measurement depth and the horizontal footprint area (Zreda et al., 2008; Franz et al., 2012a; Desilets and Zreda, 2013), (iv) the standard $N_{0}$-calibration function for soil moisture estimation, presented below (Desilets et al., 2010), and (v) the universal calibration function (Franz et al., 2013b). Most of these studies considered ground-level epithermal neutrons (neutron 


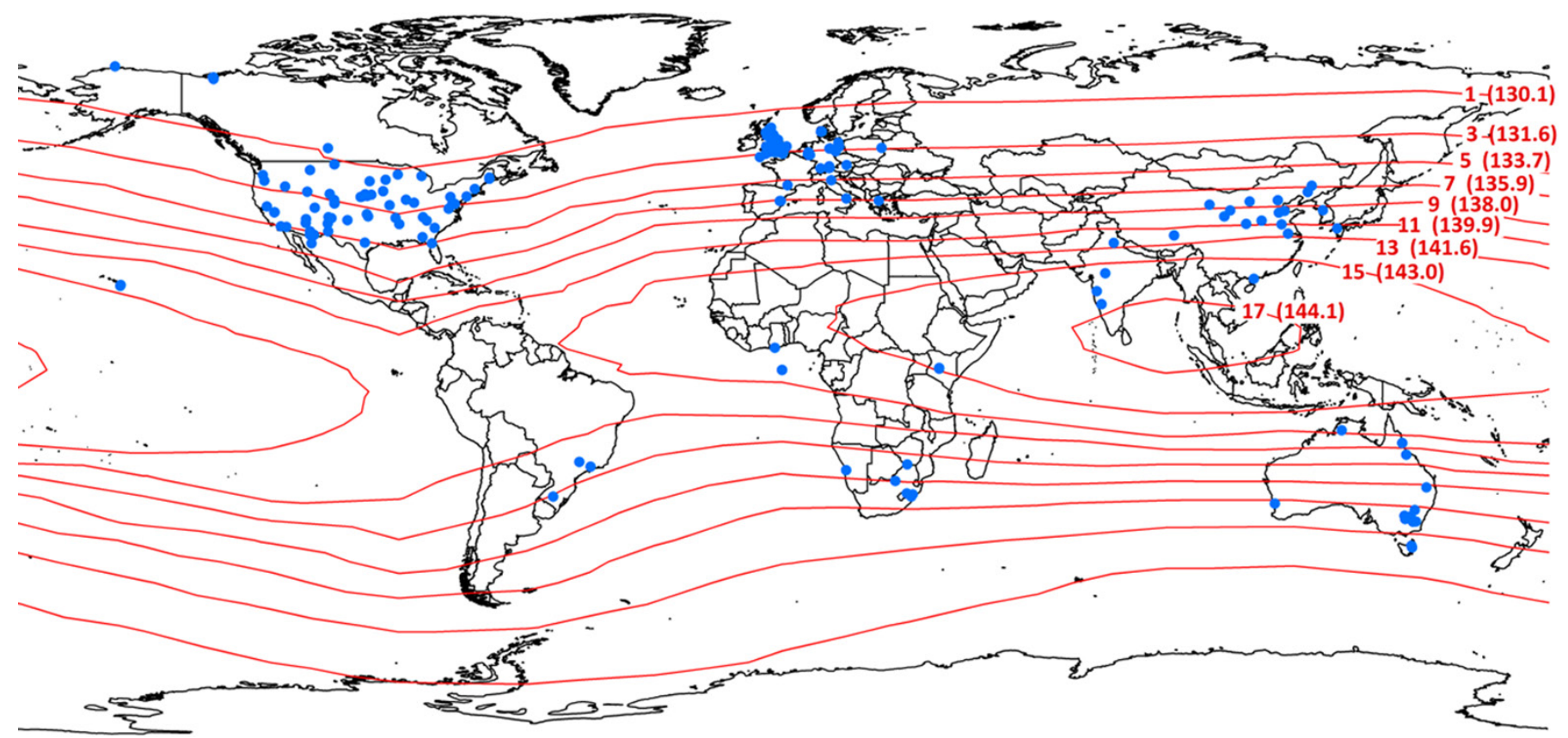

Fig. 1. Cosmic-ray neutron stations (blue points), the cutoff rigidity of 2010 (in $\mathrm{GeV}$, red lines; numbers in front of parentheses) and the attenuation length (in $\mathrm{g} / \mathrm{cm}^{2}$, red lines; numbers in parentheses). The cutoff rigidity was calculated using the COSMOS utility (http://cosmos.hwr.arizona.edu/ Util/rigidity.php), which uses the methods of Smart and Shea (2001). The attenuation lengths are between atmospheric depths of $1033 \mathrm{and} 933 \mathrm{~g} / \mathrm{cm}^{2}$ and were calculated based on Desilets et al. (2006).

energies $10-100$ or $10-1000 \mathrm{eV}$ ) using model setups of bare ground conditions and silica soil, while Zreda et al. (2008) performed simulations for four different soil types and included both thermal (median energy of $0.025 \mathrm{eV}$ ) and epithermal-fast neutrons (neutron energies $1-10^{6} \mathrm{eV}$ ). The epithermal regime is not well defined and therefore different energy ranges are considered by different studies.

For the application of the $\mathrm{CRN}$ soil moisture method, it is important to understand the footprint area of the neutron detector. Using a diffusion theory framework and MCNPX neutron transport modeling, the footprint radius was found to be approximately $300 \mathrm{~m}$ for $86.5 \%$ of the neutron counts (Desilets and
Zreda, 2013). The results were achieved by applying a cosmicray particle source at ground level and measuring the average distance traveled by the neutrons. The effect of soil moisture on the footprint size was found to be small, while the dependence of atmospheric water vapor was significant as the radius decreased by $20 \mathrm{~m}$ for every $0.01 \mathrm{~kg} / \mathrm{kg}$ increase in specific humidity. Köhli et al. (2015) used the Ultra Rapid Adaptable Neutron-Only Simulation (URANOS) model to investigate the CRN footprint by releasing neutrons from point sources randomly distributed in a layer from 2 to $42 \mathrm{~m}$ above the ground surface. They found a substantially smaller footprint radius ranging from 130 to 240 $\mathrm{m}$, with a strong dependence on atmospheric water vapor, soil moisture, and vegetation biomass.

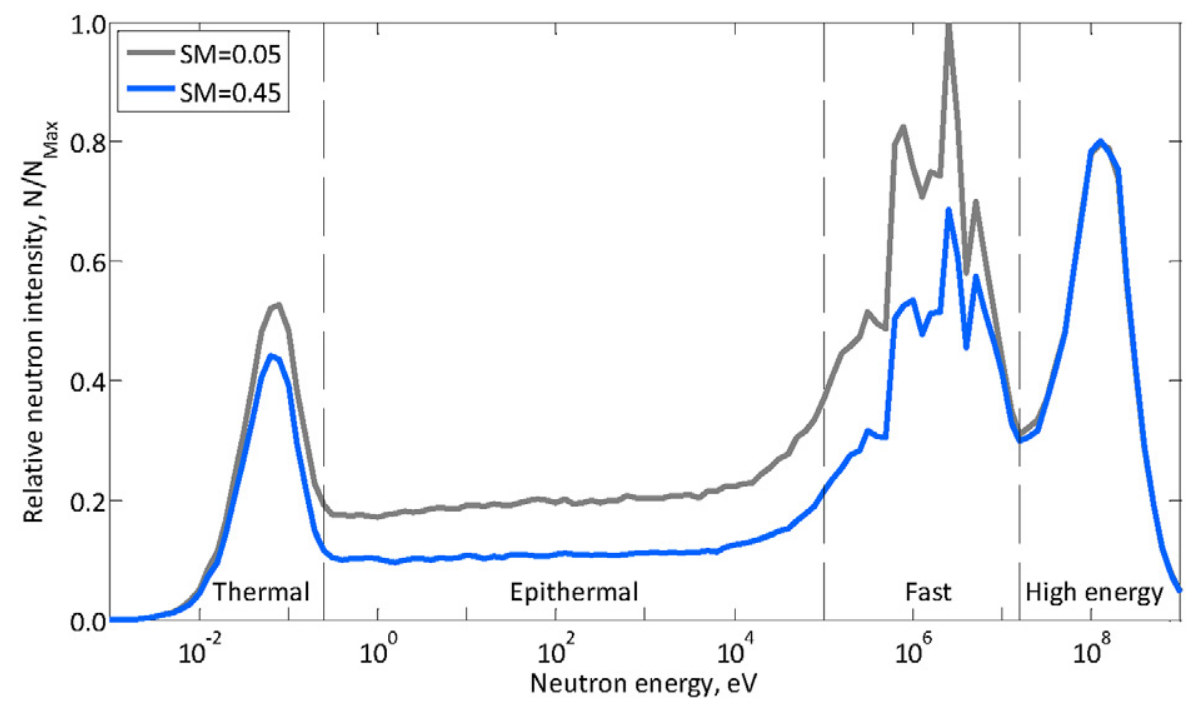

Fig. 2. Ground level (1.5 m above the ground surface) energy spectra of cosmic-ray neutrons at volumetric soil moisture (SM) of 0.05 and 0.45 at an agricultural field site in western Denmark (bare ground conditions). The spectra are modeled using a modified model setup of Andreasen et al. (2016). The neutron transport model MCNP6 was used with the galactic cosmic-ray source option (McKinney et al., 2012). 

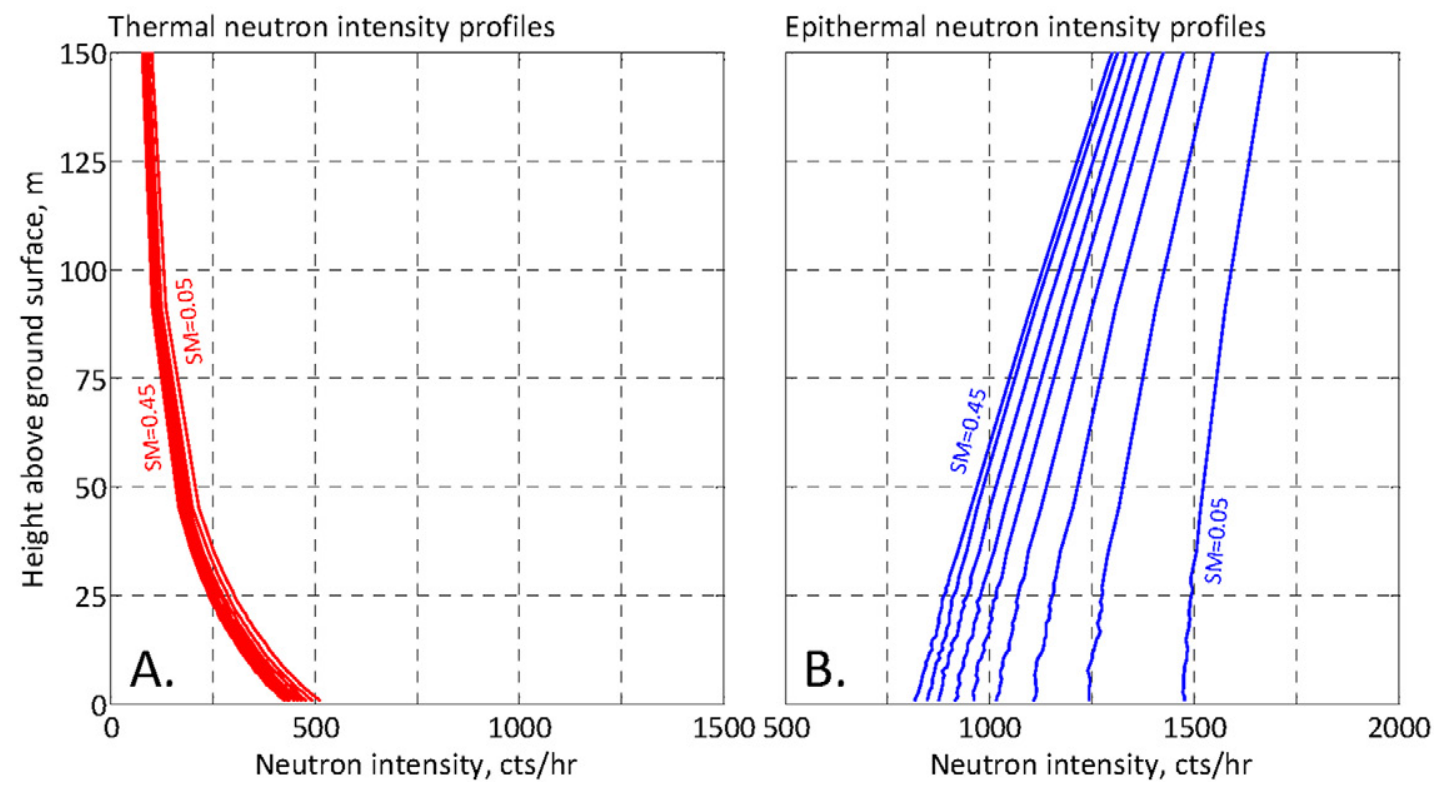

Fig. 3. Modeled (A) thermal and (B) epithermal neutron intensity profiles at volumetric soil moisture (SM) of 0.05 to 0.45 (at 0.05 increments) at an agricultural field site in western Denmark (bare ground conditions) using the neutron transport model MCNP6 (Voulund Farmland model from Andreasen et al., 2016). The decrease in neutron intensity follows an increase in soil moisture.

\section{Correcting Neutron Intensity}

The ground-level neutron intensity varies with changes in barometric pressure, incoming cosmic radiation, and atmospheric water vapor (Bethe et al., 1940; Simpson, 1951; Kodama et al., 1979; Kodama, 1980). Therefore, correction models have been developed to correct measured neutron intensities to arbitrary reference conditions.

The following correction factor for barometric pressure $\left(f_{\mathrm{p}}\right)$ can be used (Zreda et al., 2012):

$$
f_{\mathrm{p}}=\exp \left(\frac{P_{0}-P}{L}\right)
$$

where $L$ is the mass attenuation length for high-energy neutrons and is a function of cutoff rigidity (Desilets et al., 2006), $P$ is the barometric pressure at the time of measurement, and $P_{0}$ is an arbitrary reference pressure. Note that the units of $L, P$, and $P_{0}$ can be shielding depth $\left(\mathrm{g} / \mathrm{cm}^{2}\right)$ or pressure $(\mathrm{Pa})$, where $1 \mathrm{~g} / \mathrm{cm}^{2}=98.0665 \mathrm{~Pa}$. If shielding depth is used, $L$ ranges from $130 \mathrm{~g} / \mathrm{cm}^{2}$ at high latitudes to $144 \mathrm{~g} / \mathrm{cm}^{2}$ at the equator (see Fig. 1).

Zreda et al. (2012) proposed a simple correction factor for incoming cosmic radiation $\left(f_{\mathrm{i}}\right)$ to be calculated by scaling the incoming neutron intensity with a reference neutron intensity:

$f_{\mathrm{i}}=\frac{I_{\mathrm{m}}}{I_{0}}$

where $I_{\mathrm{m}}$ is the incoming neutron intensity that can be retrieved from the neutron monitor database (nmdb.eu) and $I_{0}$ is an arbitrary baseline reference intensity. The number of neutron monitors is limited, especially in the southern hemisphere. Hawdon et al. (2014) demonstrated that neutron monitors of similar cutoff rigidities to the location of neutron detection provide accurate corrections for incoming cosmic radiation. Therefore, more detailed correction procedures are not necessary for cases where no neutron monitor is located nearby.

Rosolem et al. (2013) developed the following correction factor for atmospheric water vapor $\left(f_{\mathrm{wv}}\right)$ :

$f_{\mathrm{wv}}=1+0.0054 \Delta \rho v_{0}$

where $\Delta \rho v_{0}\left(=\rho v_{0}-\rho v_{0 \_ \text {ref }}\right.$, in $\left.\mathrm{g} / \mathrm{m}^{3}\right)$ is the difference in the absolute humidity at the time of measurement $\left(\rho v_{0}\right)$ and at an arbitrary reference time $\left(\rho v_{0}\right.$ ref $)$.

Finally, the corrected neutron intensity $\left(N_{\text {cor }}\right)$ can be calculated from the measured neutron intensity $(N)$ of the moderated detector and the correction factors for barometric pressure, incoming cosmic radiation, and atmospheric water vapor:

$N_{\text {cor }}=\frac{N f_{\mathrm{wv}}}{f_{\mathrm{p}} f_{i}}$

The measurement uncertainty is related to the measured neutron count rate $N$ and follows Poissonian statistics. The variance equals the count rate $N$, the standard deviation is $N^{0.5}$, and the coefficient of variation is $N^{-0.5}$. Thus, the relative measurement uncertainty decreases with increasing count rate. 


\section{Measuring Soil Moisture Using Cosmic-Ray Neutrons}

A proportional gas tube can be used to measure thermal neutrons (bare detector). By encasing the gas tube with common plastic (moderated detector), epithermal neutrons are moderated down to thermal energies and are thereby detected. Note that the bare detector has an epithermal contribution ( $5 \%$ of the epithermal neutron intensity measured by the moderated detector), while the moderated detector has a thermal contribution ( $45 \%$ of the thermal neutron intensity measured by the bare detector). This is important to consider when measuring over seawater or for a profile of multiple heights because the absolute contribution varies with salinity (because $\mathrm{Cl}^{-}$has a high thermal neutron absorption cross-section) and with height, respectively (Andreasen et al., 2016).

Corrected moderated neutrons can be converted to soil moisture using the standard $N_{0}$-calibration function developed by Desilets et al. (2010):

$\theta\left(N_{\text {cor }}\right)=\frac{a_{0}}{\left(N_{\text {cor }} / N_{0}\right)-a_{1}}-a_{2}$

where $\theta$ is the soil moisture, $N_{\text {cor }}$ is the corrected moderated neutron intensity in counts per time unit from Eq. [4], $N_{0}$ is the moderated neutron intensity over dry soil in counts per time unit, and $a_{i}$ are parameters $\left(a_{0}=0.0808, a_{1}=0.372\right.$, and $\left.a_{2}=0.115\right)$. The $N_{0}$ parameter may be estimated from soil moisture calibration campaigns. Zreda et al. (2012) proposed that the calibration of a neutron detector at sea level should be based on a total of 108 volumetric soil samples taken at 18 locations at radial distances of 25,75 , and $175 \mathrm{~m}$ at every $60^{\circ}$ (from $0-360^{\circ}$ ) and across the depth interval 0 to $30 \mathrm{~cm}$ ( $5-\mathrm{cm}$ increments). These radial distances increase with increasing altitude due to changes in the footprint as a function of barometric pressure (Franz et al., 2012b). Each sampling location is given equal weight for calculating the area-average volumetric soil moisture. The greater sensitivity to neutrons originating closer to the point of detection (Zreda et al., 2008) is accounted for by the prevalence of sampling locations closer to the neutron detector. Köhli et al. (2015) and Schrön et al. (2017) suggested that the calibration should be adapted according to the horizontal footprint and distance weighting, which apart from the barometric pressure, also depends on the atmospheric water vapor, soil moisture, and vegetation. Compared with the equal weighting of independent soil moisture measurements suggested by Franz et al. (2012b), improved soil moisture estimates were obtained by applying a weighting function (Schrön et al., 2017). In principle, a single calibration campaign is adequate; however, when additional pools of $\mathrm{H}$ are present, two or more campaigns at different soil water contents will produce better calibration (Franz et al., 2012b, 2013a, 2016; Lv et al., 2014; Iwema et al., 2015; Heidbüchel et al., 2016). Finally, an alternative calibration function for soil moisture estimation was developed by Franz et al. (2013b). This function was derived to accommodate field sites and roving campaigns where soil sampling is impossible or impractical and it is usually referred to as the universal calibration function. The universal calibration method will most often benefit from spatial maps of soil bulk density, lattice water, soil organic C, and biomass. Some of these are available from other sources or can be determined based on database libraries (Avery et al., 2016).

\section{Assessment and Application of the Cosmic-Ray Neutron Soil Moisture Method}

Since the introduction of the method in 2008, 194 stationary cosmic-ray neutron stations have been installed worldwide (Fig. 1), and several CRN rovers have been put into use. The main clusters of stationary neutron detectors are the COSMOS network, with most stations in the United States (73 stations in the United States) (Zreda et al., 2012), the United Kingdom COSMOS-UK network (32 stations) (Evans et al., 2016), the Australian CosmOz network (13 stations) (Hawdon et al., 2014), and the TERENO network, with most stations in Germany (20 stations in Germany) (Baatz et al., 2014). Data from these networks are freely available (cosmos.hwr.arizona.edu, cosmos.ceh.ac.uk, cosmoz.csiro.au, and teodoor.icg.kfa-juelich.de/overview-en), as are data from many of the other installations.

The CRN method was assessed by comparing the derived soil moisture obtained using stationary neutron detectors with areaaverage soil moisture measurements obtained from oven drying (Zreda et al., 2008, 2012; Zhu et al., 2016) and from in situ sensor networks (Rivera Villarreyes et al., 2011; Franz et al., 2012a, 2012b, 2016; Bogena et al., 2013; Lv et al., 2014; Zhu et al., 2015, 2016; Schreiner-McGraw et al., 2016). The method was successfully demonstrated for various land cover types, soil types, and climates. Offsets and periodic misfits between CRN soil moisture and independent measurements were explained by inadequate in situ sensor networks for representing the neutron detector footprint and by the differences in the measurement depth of the various soil moisture methods. Furthermore, overestimated CRN soil moisture was explained by the presence of other $\mathrm{H}$ pools (e.g., vegetation, snow), flooding irrigation, poor neutron counting statistics (e.g., at low latitudes and low elevation), and the varying measurement depth of the neutron detector. Improved comparability of CRN soil moisture and in situ sensor network measurements was obtained when the effect of biomass was considered by including leaf area index measurements in the $\mathrm{CRN}$ soil moisture estimation (Coopersmith et al., 2014). Adjusting the $a_{i}$ parameters (Eq. [5]) was also found to provide more accurate CRN soil moisture estimates (Rivera Villarreyes et al., 2011; Lv et al., 2014; Heidbüchel et al., 2016). Field-scale root zone soil moisture (top $1 \mathrm{~m}$ of the unsaturated zone) was estimated by coupling CRN estimates with soil moisture from a single time-stable station (the time stability approach). The estimates compared well against point measurements taken at 21 locations within the neutron detector footprint (Peterson et al., 2016). Cosmic-ray neutron soil moisture was used in water balance 
studies and proved useful for estimating infiltration and evapotranspiration (Franz et al., 2014; Schreiner-McGraw et al., 2016). Schreiner-McGraw et al. (2016) found the relationship between CRN soil moisture and actual evapotranspiration to be similar to those obtained by other studies under similar environmental conditions. Foolad et al. (2017) determined soil hydrological parameters at a spatial scale appropriate for field- and regional-scale studies from inverse modeling using CRN soil moisture estimates. Based on the parameter optimized model, they obtained simulated actual evapotranspiration in reasonable agreement with independent measurements from an eddy covariance tower. Furthermore, soil moisture was predicted accurately (in agreement with independent measurements) and effectively (with minimum training) by combining machine learning and soil moisture estimates from a CRN detector and from an in situ sensor network (Almeida et al., 2014).

Mapping of soil moisture using a CRN rover was demonstrated by Desilets et al. (2010), Chrisman and Zreda (2013), and Dong et al. (2014). The two latter studies effectively calibrated the rovers to map surface soil moisture $(0-5 \mathrm{~cm})$ and provided products over an area relevant for calibration and validation of satellite microwave remote sensing missions like SMOS and SMAP (Ochsner et al., 2013). Furthermore, soil moisture estimates at various spatial resolutions $(1,3$, and $12 \mathrm{~km})$ were obtained by combining data from stationary CRN detectors and roving surveys (Franz et al., 2015) to satisfy demand for soil moisture products at different spatial scales.

The performance of satellite and modeling products was assessed using CRN soil moisture data sets (Kim et al., 2015; Evans et al., 2016; Kędzior and Zawadzki, 2016; Vinodkumar et al., 2017; Montzka et al., 2017). Overall, CRN soil moisture was found to be appropriate for validation and for identifying areas of improvement in the parameterizations and the model for the retrieval algorithms. Still, a systematic deviation between CRN-derived and remotely sensed soil moisture may exist due to horizontal and vertical scale mismatch in areas with heterogeneous soil moisture and vegetation (Montzka et al., 2017). Regional-scale soil moisture data from the Australian CRN network was furthermore found useful for wildfire management and warning (Vinodkumar et al., 2017).

For data assimilation applications, the COsmic-ray Soil Moisture Interaction Code (COSMIC), a physically based forward operator, was developed to model the interaction between CRNs and soil moisture (Shuttleworth et al., 2013). The COSMIC operator was successfully used for data assimilation of CRNs into land surface models (Han et al., 2014, 2015, 2016; Rosolem et al., 2014; Baatz et al., 2017). Rosolem et al. (2014) used synthetic observations of aboveground CRNs in the COSMIC operator to update soil moisture states in the Noah land surface model. The performance of the Noah land surface model was improved in the root-zone soil layers $(0-100 \mathrm{~cm})$ by including CRN data sets. Han et al. (2014) used COSMIC to model the neutron count and found the retrieved hourly soil moisture to agree well with measurements from an in situ sensor network. Assimilating CRN intensity data using the COSMIC operator into the Community Land Model (CLM) was found to improve soil moisture and evapotranspiration estimation significantly at a field location with no available information on irrigation (Han et al., 2015). In a synthetic study, soil hydraulic parameters were updated by assimilation of CRNs, providing an improved soil moisture characterization (Han et al., 2016). Baatz et al. (2017) successfully assimilated neutron intensity time series from a network of CRN detectors in the CLM model, which also led to improved soil moisture characterization.

\section{Estimating Snow Water Equivalent}

Because neutrons are sensitive to all sources of $\mathrm{H}$ at the land surface, the CRN detector can also be used to survey snow. This has been done using a neutron detector installed on the ground surface (Kodama et al., 1979; Kodama, 1980) or a few meters above it (same setup as for CRN soil moisture measurements) (Desilets et al., 2010; Sigouin and Si, 2016; Schattan et al., 2017; Desilets, 2017).

Snow becomes the dominant control on neutron intensity even when present in small quantities because it is a concentrated layer of $\mathrm{H}$ placed at the land surface. For the CRN detector installed above the snow cover, just $1 \mathrm{~cm}$ of snow water equivalent (SWE) can reduce the neutron counting rate by $10 \%$ or more, depending on soil moisture under the snow pack. Based on neutron transport modeling, the CRNs were found to be affected by snow even if the snow was at some distance from the CRN detector (Zweck et al., 2013). Nonlinear regression functions were determined to link both snow depth and SWE to CRN intensity (Schattan et al., 2017). Time series of CRN-derived SWE was found to correspond well with data from snow surveys conducted within the detector footprint and snow depth measurements at field sites nearby (Sigouin and Si, 2016). The large footprint of the sensor proved useful in characterizing the highly heterogeneous snow pack and probably better represented the area-wide snow dynamics than a snow pillow providing measurements at a local scale (Desilets, 2017). As with all SWE monitoring methods, the CRN technique for measuring SWE has its limitations. The most notable of these are the inability to distinguish SWE dynamics from soil moisture dynamics and the limited amount of SWE that can be measured. From neutron transport modeling, this limit was found to be around 100- to 150-mm SWE (Desilets, 2017). Schattan et al. (2017) conducted measurements in an alpine terrain in Austria and found the uncertainty of CRN snow depth and SWE measurements to increase with increasing snow cover. Reasonably low measurement uncertainties were obtained up to $100-\mathrm{mm}$ SWE.

In addition, snow measurements have also been obtained using a neutron detector installed at the ground surface and therefore buried at snowfall (Kodama et al., 1979; Kodama, 1980). In this case, the response area is of meters, and this is caused by the short mass distance that CRNs can traverse in snow compared with air 
(Zreda et al., 2012). The SWE limit is significantly higher for a snow-covered neutron detector and enables measurements of $>1 \mathrm{~m}$ of SWE. The SWE limit is higher because the energy spectrum is different for downward and upward moving neutrons. The neutron intensity below the snow pack is influenced by the attenuation of high-energy neutrons in addition to epithermal neutrons from the atmosphere. Because high-energy neutrons have a longer attenuation length than epithermal neutrons, a thicker layer of snow can be measured when high-energy neutrons are included in the flux. By contrast, the CRN detector installed above the snow pack measures the attenuation by snow of upward-moving neutrons. Because few if any high-energy neutrons are included in the upward flux, the neutrons tend to be less penetrating, and only smaller amounts of SWE can be measured.

\section{The Environmental Effect}

\section{Sources of Uncertainty}

The term environmental effect refers to the influence of the specific properties and settings of a field site on the neutron transport and intensity. This includes vegetation, organic litter, soil composition and layering, canopy interception, snow, lakes and streams, and buildings and roads. Different features influence neutron transport differently due to their varying materials (i.e., chemical composition and density), different distribution within the footprint area (below and above the ground surface), as well as their different temporal behavior (static, quasi-static, and dynamic) (Table 1).

Multiple studies have examined the effect of these features on neutron intensity. When additional $\mathrm{H}$ pools are temporally stable, their influence on neutron intensity can be amended by estimating the contribution of each source and subtracting its contribution during the transformation of the neutron counts into volumetric soil moisture contents (Zreda et al., 2012). Bogena et al. (2013) showed that more complex corrections are needed in the case where $\mathrm{H}$ pools also vary with time, e.g., water content of the litter layer or vegetation biomass.

Forest biomass and litter at the forest floor were found to be sources of uncertainty for both stationary CRN detectors and rover systems. Including the effect of litter in the $N_{0}$-calibration function provided more accurate soil moisture estimates (Bogena et al., 2013). A strong correlation of biomass and the $N_{0}$ parameter (the CRN intensity over dry soil) was reported in several studies (Hornbuckle et al., 2012; Franz et al., 2013c; Hawdon et al., 2014; Baatz et al., 2014, 2015). Baatz et al. (2015) used linear regression to determine an empirical biomass correction model for Norway spruce [Picea abies (L.) Karst.]. Similarly, Franz et al. (2015) found a linear relationship based on measurements for maize (Zea mays L.) and soybean [Glycine max (L.) Merr.], finding a $1 \%$ decrease in $N_{0}$ for every $1 \mathrm{~kg} / \mathrm{m}^{2}$ of biomass or water equivalent present. Based on measurements from the CosmOz network, Hawdon et al. (2014) presented a nonlinear relationship with $N_{0}$ for biomass greater than $\sim 8 \mathrm{~kg} / \mathrm{m}^{2}$. Tian et al. (2016) found linear relationships of maize vegetation and snow, and the ratio of the neutron intensity measured with bare and moderated detectors. Based on these findings, they presented an approach for correcting for the effect of aboveground H. In addition, Baroni and Oswald (2015) presented a simple scaling approach based on the relationship of CRN soil moisture estimates and in situ soil moisture measurements to correct for the influence of crop biomass and canopy interception on neutron intensity.

\section{Opportunities to Capitalize}

on the Environmental Effects

The sensitivity of neutron intensity to different $\mathrm{H}$ pools also presents an opportunity to use CRN measurements to assess other relevant hydrological components, including biomass, canopy interception, and snow (Table 1). The universal calibration function presented by Franz et al. (2013b) is applicable for any $\mathrm{H}$ pool and was used to quantify biomass at a forest and a cultivated maize field site (Franz et al., 2013c). The signal of biomass on the neutron intensity was isolated by quantifying the non-biomass $\mathrm{H}$ pools independently, and the study demonstrated the utility of the method because the biomass estimates agreed reasonably with independent measurements. Still, the method included several assumptions regarding the distribution of the various $\mathrm{H}$ pools (e.g., biomass, litter layers, and canopy interception) that needed to be estimated independently. Obtaining independent measurements across an area comparable to the CRN footprint is time consuming, tedious, and often uncertain. In addition to the uncertainties of the various methods, implicit assumptions about the known footprint area and weighting are included in the quantification of the various components.

The environmental effect was also examined based on site-specific neutron transport modeling using the MCNPX code, the Monte Carlo N-Particle transport code version 6 (MCNP6), and measurements (Andreasen et al., 2016, 2017). The influence of soil moisture on neutron intensity was found to be reduced with high amounts of biomass and litter layer. The fact that CRN soil moisture estimation is less favorable at forest field sites is in agreement with the findings of Bogena et al. (2013) and Baatz et al. (2015). Including a thin litter layer in the model was also found to change the neutron intensities significantly. This suggests that litter is important not only at forest field sites where it is thick but also at agricultural field sites with a seasonal change in litter layer thickness. Ground-level thermal/epithermal neutron ratios were found to increase with increasing amounts of biomass independent of soil moisture (Andreasen et al., 2017). This relationship may be used to estimate biomass from CRN measurements alone. Furthermore, the neutron response to specific features (e.g., biomass, litter, soil composition) was found to vary and was dependent on all the environmental features present at a field site (Andreasen et al., 2016, 2017). 


\section{Challenges and Potential Improvements}

\section{Neutron Detector Footprint}

As mentioned above, footprint analysis results were presented by both Desilets and Zreda (2013) and Köhli et al. (2015). These results were based on different models (MCNPX and URANOS, respectively), different spectra of cosmic-ray particles, and somewhat different theoretical and conceptual frameworks. Furthermore, the source and release of the particles were specified differently. Experimental verification has been limited for both approaches, and future studies have been recommended to examine the model results with greater detail. The footprint area was found to be sensitive to the environmental settings regardless of the model code. Changes in atmospheric water vapor, barometric pressure, vegetation cover, and soil moisture all affect the footprint size. In addition, temporal variations in the $\mathrm{H}$ pools (soil moisture variation, snowfall and snowmelt, and vegetation growth and harvest) impact the spatial sensitivity. A procedure to account for a changing footprint area is especially relevant for CRN roving products, where the variability in soil moisture and land cover can be more abrupt because the instrument traverses space. In addition, dry roads also influence the neutron intensity (Franz et al., 2015; Köhli et al., 2015). The dry road will be overrepresented in the measured neutron intensity because the sensitivity of neutron intensity to $\mathrm{H}$ is greater at the dry end (see Fig. 3, where the change in neutron count is largest going from 0.05 to 0.10 volumetric soil moisture). The road effect is dependent on road type (depth and composition) and road width. Thick and wide roads will contribute more to the CRN signal than more shallow and narrow roads. We recommend future research to address these issues.

Few studies have documented the potential of including measurements of thermal neutrons (measured using the bare detector). For this to become standard practice, fundamental theoretical studies, concerning in particular footprint and atmospheric water vapor effects, are needed. Furthermore, bare and moderated sensors are being deployed at multiple heights above the ground (e.g., towers, helicopters, and balloons), and footprint-analysis and water-vapor correction factors at these height levels should also be derived.

\section{Neutron Signal Separation}

If multiple sources of $\mathrm{H}$ are present, it is important to find ways to separate them from one another to quantify the source of interest. For example, improved accuracy of CRN soil moisture estimates at field locations with seasonally varying vegetation cover (a cropped maize field) and high amounts of vegetation biomass (forest field sites) was obtained by adapting the $a_{i}$ parameters of the $N_{0}$-calibration function (Rivera Villarreyes et al., 2011; Lv et al., 2014; Heidbüchel et al., 2016). However, the physical meaning of the $a_{i}$ parameters is lost by this adjustment. An alternative approach for advancement of the soil moisture method is to improve understanding of the various $\mathrm{H}$ pools affecting the neutron signal and to account for these in a more direct manner. To estimate multiple variables solely from neutron intensity measurements, we need to separate the time- and space-dependent effects on the measured neutron intensity. This may be enabled by an improved understanding of the neutron detector measurements, as well as combined use of neutron transport measurements and modeling. Several studies identified the benefits of combining measurements of bare and moderated neutron detectors (Desilets et al., 2010; Zreda et al., 2012; Tian et al., 2016; Andreasen et al., 2017). However, explaining the response of the detectors separately, as well as jointly, is difficult because of insufficient knowledge of the detector energy response. The neutron energy response is a continuous distribution spanning a wider energy range with varying sensitivity. As a result, the neutrons measured by bare and moderated detectors have both a thermal and an epithermal component (McJannet et al., 2014; Andreasen et al., 2016). This is problematic due to the different physical behaviors of the two energy ranges, as described above. Therefore, well-defined measurements of thermal and epithermal neutrons would help the interpretation because the signal of each environmental effect would be emphasized. Applying the recently developed neutron energy correction factors (Andreasen et al., 2016), providing purer thermal and epithermal neutron signals, may be limited to the specific soil type and/or the neutron detectors used to derive the correction factors. Repeating the field experiment using different neutron detector systems at different environmental settings may clarify the application. Additionally, more well-defined energy ranges may be inferred from measurements using a neutron spectrometer composed of detectors of various moderator thicknesses (e.g., Bonners Spheres) (Hubert et al., 2016). An alternative approach is to model the response of neutron detectors using information on the composition and the dimension of the neutron detectors. This practice would provide detailed information on the distribution of detected neutron energies and make measurements and modeling directly comparable.

Site-specific modeling of CRN transport is valuable to analyze the influences of different $\mathrm{H}$ pools on CRN signals (e.g., vegetation and canopy interception). Because the conceptualization of real field situations is challenging, modeling should be accompanied by CRN measurements to validate the model results. An initial study combining neutron height profile measurements and modeling showed that the forest canopy conceptualization has a major impact on the results (Andreasen et al., 2017). The forest geometry is complex, and identifying the proper conceptualization was not apparent from measurements. Future work should also address this challenge.

\section{Uncertainties in Cosmic-Ray Neutron Measurements of Other Hydrogen Pools}

To obtain robust CRN methods for the determination of vegetation and canopy interception, measurement uncertainties and unfavorable behavior must be explained and handled. Biomass 
water equivalents (BWE) estimated from neutron intensity ratios measured using bare and moderated detectors was found to change with time (Tian et al., 2016). Daily and weekly changes in BWE were suggested to be a result of variations in the vegetation storage of water. The storage is high during wet periods and low in times of drought, causing plants to suffer from water loss. Shortterm variations in BWE (hourly time scale) were provided during precipitation events as neutron measurements are affected by the additional $\mathrm{H}$ intercepted in the canopy. Andreasen et al. (2017) used neutron transport modeling to examine the sensitivity of neutron intensity to canopy interception. They found that canopy interception resulted in increased ground-level thermal neutron intensity and thereby an increase in the ground-level thermal/epithermal neutron intensity ratio. However, the change was found to be small, and relatively high neutron count rates were required to identify the signal of canopy interception using conventional detectors. This can be obtained from longer integration time or the use of more neutron detectors. The signal of processes acting on a short time scale (e.g., evaporation of canopy interception) may disappear if measurements are integrated for longer periods. Future studies have been recommended to examine the optimal range for integration of neutron counts at specific field sites, thereby ensuring low measurement uncertainty at an adequate representation of hydrological conditions (Rosolem et al., 2014). Additionally, this also requires an improved understanding of the processes acting on different temporal scales.

\section{Cosmic-Ray Neutron Applications}

\section{Stationary Cosmic-Ray Neutron Detection}

The application of CRN measurements for snow detection holds significant potential for hydrology and is under investigation. We anticipate that the sensitivity of neutron intensity to SWE, its dependency on soil moisture, and the range of applicability will soon be settled.

Montzka et al. (2017) identified some challenges in validating satellite-retrieved soil moisture using CRN detectors. Satelliteretrieved soil moisture was lower than CRN measurements during periods with considerable amounts of biomass. To improve the comparability at sites with a seasonally changing vegetation cover, the signal of biomass on the cosmic-ray neutron intensity must be identified and separated. As mentioned above, differences in the spatial scale of satellite retrievals and CRN measurements were found to be problematic in areas characterized by large spatial variability in the absolute soil moisture. Here, more CRN detector stations or frequent roving surveys are required for reliable satellite validation.

\section{Mobile Surveys}

In addition to supporting future high-resolution land surface modeling needs (Chaney et al., 2016a), the cosmic-ray rover provides further opportunities in commercial activities, most notably precision agriculture (Finkenbiner, 2017). For example, the mounting of rovers on existing farm equipment (sprayers, tractors, etc.), autonomous farm vehicles, or rotating infrastructure (e.g., center-pivot irrigation systems) offers interesting sensing possibilities. The piggy-backing of data collection with existing farm operations may provide a cost-effective strategy to help inform agricultural activities, such as the timing and spatial distribution of irrigation depths, soil strength estimates for re-entry time and the location of heavy machinery, optimal fertilizer timing and spatial application, optimal seed planting timing, seed planting density, and seed cultivar selection. In addition, the sensor would be useful in digital soil mapping efforts underway across the globe (McBratney et al., 2003) and validation of existing high-resolution products (cf. Polaris, Chaney et al., 2016b). Furthermore, mounting of probes to mail delivery trucks, self-driving vehicles, and commercial or passenger trains would provide repeatable local and regional mapping opportunities in natural and human-dominated landscapes. While the roving probe is fairly heavy $(>50 \mathrm{~kg})$ and miniaturization somewhat limited, the use of drone swarms with several smaller probes acting functionally as a single unit would further increase possible mapping applications. Including these data sets may lead to better statistical models and the prediction of key information such as optimal fertilizer inputs, optimal water inputs, and crop yield forecasts.

\section{Summary}

Since the introduction of the CRN method in 2008, the CRNbased method for soil moisture sensing has been an active area of research. The method has proven valuable for hydrology, especially for field- and regional-scale hydrological modeling, data assimilation, water balance studies, precision agriculture, and calibration and validation of satellite products.

Future research can both improve the accuracy of the soil moisture estimates and extend the application to include vegetation, canopy interception, and snow estimation. Cosmic-ray research within environmental science can evolve by improving our understanding of the environmental effect on low-energy neutron transport. We expect the development to include an increased use of neutron transport modeling, as well as measurements of neutrons at different and multiple energy ranges. Advancing the CRN method will benefit CRN detection at more complex field sites and in roving applications.

\section{References}

Almeida, A.C., R. Dutta, T.E. Franz, A. Terhorst, P.J. Smethurst, C. Baillie, and D. Worledge. 2014. Combining cosmic-ray neutron and capacitance sensors and fuzzy inference to spatially quantify soil moisture distribution. IEEE Sens. J. 14:3465-3472. doi:10.1109/JSEN.2014.2345376

Andreasen, M., K.H. Jensen, D. Desilets, M. Zreda, H. Bogena, and M.C. Looms. 2017. Cosmic-ray neutron transport at a forest field site: The sensitivity to various environmental conditions with focus on biomass and canopy interception. Hydrol. Earth Syst. Sci. 21:1875-1894. doi:10.5194/hess-21-1875-2017

Andreasen, M., K.H. Jensen, M. Zreda, D. Desilets, H. Bogena, and M.C. Looms. 2016. Modeling cosmic ray neutron field measurements. Water Resour. Res. 52:6451-6471. doi:10.1002/2015WR018236 
Avery, W.A., C. Finkenbiner, T.E. Franz, T. Wang, A.L. Nguy-Robertson A. Suyker, et al. 2016. Incorporation of globally available datasets into the roving cosmic-ray neutron probe method for estimating field-scale soil water content. Hydrol. Earth Syst. Sci. 20:3859-3872. doi:10.5194/hess-20-3859-2016

Baatz, R., H.R. Bogena, H.-J.H. Franssen, J.A. Huisman, C. Montzka, and H. Vereecken. 2015. An empirical vegetation correction for soil moisture content quantification using cosmic ray probes. Water Resour. Res. 51:2030-2046. doi:10.1002/2014WR016443

Baatz, R., H.R. Bogena, H.-J.H. Franssen, J.A. Huisman, W. Qu, C. Montzka and $\mathrm{H}$. Vereecken. 2014. Calibration of a catchment scale cosmic ray probe network: A comparison of three parameterization methods. J. Hydrol. 516:231-244. doi:10.1016/j.jhydrol.2014.02.026

Baatz, R., H.-J.H. Franssen, X. Han, T. Hoar, H.R. Bogena, and H. Vereecken 2017. Evaluation of a cosmic-ray neutron sensor network for improved land surface model prediction. Hydrol. Earth Syst. Sci. 21:2509-2530. doi:10.5194/hess-21-2509-2017

Baroni, G., and S.E. Oswald. 2015. A scaling approach for the assessment of biomass changes and rainfall interception using cosmic-ray neu tron sensing. J. Hydrol. 525:264-276. doi:10.1016/j.jhydrol.2015.03.053

Bethe, H.A., S.A. Korff, and G. Placzek. 1940. On the interpretation of neutron measurements in cosmic radiation. Phys. Rev. 57:573-587. doi:10.1103/PhysRev.57.573

Bogena, H.R., J.A. Huisman, R. Baatz, H.-J.H. Franssen, and H. Vereecken. 2013. Accuracy of the cosmic-ray soil water content probe in humid forest ecosystems: The worst case scenario. Water Resour. Res. 49:5778-5791. doi:10.1002/wrcr.20463

Bogena, H.R., J.A. Huisman, A. Güntner, C. Hübner, J. Kusche, F. Jonard, et al. 2015. Emerging methods for noninvasive sensing of soil moisture dynamics from field to catchment scale: A review. Wiley Interdiscip. Rev.: Water 2:635-647. doi:10.1002/wat2.1097

Chaney, N.W., P. Metcalfe, and E.F. Wood. 2016a. HydroBlocks: A fieldscale resolving land surface model for application over continental extents. Hydrol. Processes 30:3543-3559. doi:10.1002/hyp.10891

Chaney, N.W., E.F. Wood, A.B. McBratney, J.W. Hempel, T.W. Nauman C.W. Brungard, and N.P. Odgers. 2016b. POLARIS: A 30-meter probabilistic soil series map of the contiguous United States. Geoderma 274:54-67. doi:10.1016/j.geoderma.2016.03.025

Chrisman, B., and M. Zreda. 2013. Quantifying mesoscale soil moisture with the cosmic-ray rover. Hydrol. Earth Syst. Sci. 17:5097-5108. doi:10.5194/hess-17-5097-2013

Coopersmith, E.J., M.H. Cosh, and C.S. Daughtry. 2014. Field-scale moisture estimates using COSMOS sensors: A validation study with temporary networks and leaf-area-indices. J. Hydrol. 519:637-643. doi:10.1016/j.jhydrol.2014.07.060

Desilets, D. 2017. Calibrating a non-invasive cosmic ray soil moisture probe for snow water equivalent. Tech. Doc. 17-01. Hydroinnova, Albuquerque, NM. doi:10.5281/zenodo.439105.

Desilets, D., and M. Zreda. 2013. Footprint diameter for a cosmic-ray soil moisture probe: Theory and Monte Carlo simulations. Water Resour. Res. 49:3566-3575. doi:10.1002/wrcr.20187

Desilets, D., M. Zreda, and T.P.A. Ferré. 2010. Nature's neutron probe: Land surface hydrology at an elusive scale with cosmic rays. Water Resour. Res. 46:W1 1505. doi:10.1029/2009WR008726

Desilets, D., M. Zreda, and T. Prabu. 2006. Extended scaling factors for in situ cosmogenic nuclides: New measurements at low latitude. Earth Planet. Sci. Lett. 246:265-276. doi:10.1016/j.epsl.2006.03.051

Dong, J., T.E. Ochsner, M. Zreda, M.H. Cosh, and C.B. Zou. 2014. Calibration and validation of the COSMOS rover for surface soil moisture measurement. Vadose Zone J. 13(4). doi:10.2136/vzj2013.08.0148

Evans, J.G., H.C. Ward, J.R. Blake, E.J. Hewitt, R. Morrison, M. Fry, et al. 2016. Soil water content in southern England derived from a cosmic ray soil moisture observing system: COSMOS-UK. Hydrol. Processes 30:4987-4999. doi:10.1002/hyp.10929

Fermi, E. 1965. Nobel lecture in physics, 1938: Artificial radioactivity produced by neutron bombardment. Nobel Lectures, Physics 1922 1941. Elsevier, Amsterdam. p. 414-421. http://www.nobelprize.org/ nobel_prizes/physics/laureates/1938/fermi-lecture.html (accessed 12 July 2017).

Finkenbiner, C.E. 2017. Integration of hydrogeophysical datasets for improvedwaterresourcemanagementinirrigatedsystems.M.S.thesis. Univ of Nebraska, Lincoln. http://digitalcommons.unl.edu/natresdiss/145

Foolad, F., T.E. Franz, T. Wang, J. Gibson, A. Kilic, R.G. Allen, and A. Suyker. 2017. Feasibility analysis of using inverse modeling for estimating field scale evapotranspiration in maize and soybean fields from soil wa- ter content monitoring networks. Hydrol. Earth Syst. Sci. 21:1263-1277. doi:10.5194/hess-21-1263-2017

Franz, T.E., A. Wahbi, M. Vreugdenhil, G. Weltin, L. Heng, M. Oismueller, et al. 2016. Using cosmic-ray neutron probes to monitor landscape scale soil water content in mixed land use agricultural systems. Appl. Environ. Soil Sci. 2016:4323742. doi:10.1155/2016/4323742

Franz, T.E., T. Wang, W. Avery, C. Finkenbiner, and L. Brocca. 2015. Combined analysis of soil moisture measurements from roving and fixed cosmic ray neutron probes for multiscale real-time monitoring. Geophys. Res. Lett. 42:3389-3396. doi:10.1002/2015GL063963

Franz, T.E., M. Zreda, T.P.A. Ferré, and R. Rosolem. 2013b. An assessment of the effect of horizontal soil moisture heterogeneity on the areaaverage measurement of cosmic-ray neutrons. Water Resour. Res. 49:6450-6458. doi:10.1002/wrcr.20530

Franz, T.E., M. Zreda, T.P.A. Ferré, R. Rosolem, C. Zweck, S. Stillman, et al. 2012a. Measurement depth of the cosmic ray soil moisture probe affected by hydrogen from various sources. Water Resour. Res. 48:W08515. doi:10.1029/2012WR011871

Franz, T.E., M. Zreda, and E.G. King. 2014. Cosmic-ray soil moisture probe: A new technology to manage African dryland ecosystems. In: L.K. Heng et al., editors, International Symposium on Managing Soils for Food Security and Climate Change Adaptation and Mitigation, Vienna. 23-27 July 2012. FAO, Rome. p. 381-386.

Franz, T.E., M. Zreda, R. Rosolem, and T.P.A. Ferré. 2012b. Field validation of a cosmic-ray neutron sensor using a distributed sensor network. Vadose Zone J. 11 (4). doi:10.2136/vzj2012.0046

Franz, T.E., M. Zreda, R. Rosolem, and T.P.A. Ferré. 2013a. A universal calibration function for determination of soil moisture with cosmic-ray neutrons. Hydrol. Earth Syst. Sci. 17:453-460. doi:10.5194/hess-17-453-2013

Franz, T.E., M. Zreda, R. Rosolem, B.K. Hornbuckle, S.L. Irvin, H. Adams, et al. 2013c. Ecosystem-scale measurements of biomass water using cosmic ray neutrons. Geophys. Res. Lett. 40:3929-3933. doi:10.1002/grl.50791

Goldhagen, P., J.M. Clem, and J.W. Wilson. 2004. The energy spectrum of cosmic-ray induced neutrons measured on an airplane over a wide range of altitude and latitude. Radiat. Prot. Dosim. 110:387-392. doi:10.1093/rpd/nch216

Han, X., R. Jin, and X. Li. 2014. Soil moisture estimation using cosmic-ray soil moisture sensing at heterogeneous farmland. IEEE Geosci. Remote Sens. Lett. 11:1659-1663. doi:10.1109/LGRS.2014.2314535

Han, X., H.J. Franssen, R. Rosolem, R. Jin, X. Li, and H. Vereecken. 2015 Correction of systematic model forcing bias of CLM using assimilation of cosmic-ray neutrons and land surface temperature: A study in the Heihe catchment, China. Hydrol. Earth Syst. Sci. 19:615-629. doi:10.5194/hess-19-615-2015

Han, X., H.-J.H. Franssen, M.Á.J. Bello, R. Rosolem, H.R. Bogena, F.M. Alzamora, A. Chanzy, and H. Vereecken. 2016. Simultaneous soil moisture and properties estimation for a drip irrigated field by assimilating cosmic-ray neutron intensity. J. Hydrol. 539:611-624. doi:10.1016/j.jhydrol.2016.05.050

Hawdon, A., D. McJannet, and J. Wallace. 2014. Calibration and correction procedures for cosmic-ray neutron soil moisture probes located across Australia. Water Resour. Res. 50:5029-5043. doi:10.1002/2013WR015138

Heidbüchel, I., A. Guntner, and T. Blume. 2016. Use of cosmic-ray neutron sensors for soil moisture monitoring in forests. Hydrol. Earth Syst. Sci. 20:1269-1288. doi:10.5194/hess-20-1269-2016

Hendrick, L.D., and R.D. Edge. 1966. Cosmic-ray neutrons near the Earth. Phys. Rev. 145:1023-1025. doi:0.1 103/PhysRev.145.1023

Hornbuckle, B., S. Irvin, T. Franz, R. Rosolem, and C. Zweck. 2012. The potential of the COSMOS network to be a source of new soil moisture information for SMOS and SMAP. In: 2012 IEEE International Geoscience and Remote Sensing Symposium (IGARSS), Munich, Germany. 22-27 July 2012. IEEE, Piscataway, NJ. p. 1243-1246. doi:10.1109/IGARSS.2012.6351317

Hubert, G., M.T. Pazianotto, and C.A. Federico. 2016. Modeling of ground albedo neutrons to investigate seasonal cosmic ray-induced neutron variations measured at high-altitude stations. J. Geophys. Res. Space Phys. 121:12186-12201. doi:10.1002/2016JA023055

Iwema, J., R. Rosolem, R. Baatz, T. Wagener, and H.R. Bogena. 2015. Investigating temporal field sampling strategies for site-specific calibration of three soil moisture-neutron intensity parameterization methods. Hydrol. Earth Syst. Sci. 19:3203-3216. doi:10.5194/hess-19-3203-2015

Kędzior, M., and J. Zawadzki. 2016. Comparative study of soil moisture estimations from SMOS satellite mission, GLDAS database, and cosmic-ray neutrons measurements at COSMOS station in eastern Poland. Geoderma 283:21-31. doi:10.1016/j.geoderma.2016.07.023 
Kim, S., Y.Y. Liu, F.M. Johnson, R.M. Parinussa, and A. Sharma. 2015. A global comparison of alternate AMSR2 soil moisture products: Why do they differ? Remote Sens. Environ. 161:43-62. doi:10.1016/j.rse.2015.02.002

Kodama, M. 1980. Continuous monitoring of snow water equivalent using cosmic-ray neutrons. Cold Reg. Sci. Technol. 3:295-303. doi:10.1016/0165-232X(80)90036-1

Kodama, M., S. Kudo, and T. Kosuge. 1985. Application of atmospheric neutrons to soil moisture measurement. Soil Sci. 140:237-242. doi:10.1097/00010694-198510000-00001

Kodama, M., K. Nakai, S. Kawasaki, and M. Wada. 1979. An application of cosmic-ray neutron measurements to the determination of the snowwater equivalent. J. Hydrol. 41:85-92. doi:10.1016/0022-1694(79)90107-0

Köhli, M., M. Schrön, M. Zreda, U. Schmidt, P. Dietrich, and S. Zacharias 2015. Footprint characteristics revised for field-scale soil moisture monitoring with cosmic-ray neutrons. Water Resour. Res. 51:5772-5790. doi:10.1002/2015WR017169

LV, L., T.E. Franz, D.A. Robinson, and S.B. Jones. 2014. Measured and mod eled soil moisture compared with cosmic-ray neutron probe estimates in a mixed forest. Vadose Zone J. 13(12). doi:10.2136/vzj2014.06.0077

McBratney, A.B., M.L.M. Santos, and B. Minasny. 2003. On digital soil mapping. Geoderma 117:3-52. doi:10.1016/S0016-7061 (03)00223-4

McJannet, D. T. Franz, A. Hawdon, D. Boadle, B. Baker, A. Almeida, et al. 2014. Field testing of the universal calibration function for determination of soil moisture with cosmic-ray neutrons. Water Resour. Res. 50:5235-5248. doi:10.1002/2014WR015513

McKinney, G.W., H. Armstrong, M.R. James, J. Clem, and P. Goldhagen. 2012. MCNP6 cosmic-source option. Paper presented at ICAPP' 12: International Congress on Advances in Nuclear Power Plants, Chicago. 24-28 June 2012. https://www.osti.gov/scitech/biblio/1044110/

Montzka, C., H.R. Bogena, M. Zreda, A. Monerris, R. Morrison, S. Muddu, and $\mathrm{H}$. Vereecken. 2017. Validation of spaceborne and modelled surface soil moisture products with cosmic-ray neutron probes. Remote Sens. $9(2): 103$. doi:10.3390/rs9020103

Ochsner, T.E., M.H. Cosh, R.H. Cuenca, W.A. Dorigo, C.S. Draper, Y. Hagimoto, et al. 2013. State of the art in large-scale soil moisture monitoring. Soil Sci. Soc. Am. J. 77:1888-1919. doi:10.2136/sssaj2013.03.0093

Pelowitz, D.B. 2011. MCNPXTM user's manual, Version 2.7.0. Rep. LACP-1 1-00438. Los Alamos Natl. Lab., Los Alamos, NM.

Peterson, A.M., W.D. Helgason, and A.M. Ireson. 2016. Estimating fieldscale root zone soil moisture using the cosmic-ray neutron probe. Hydrol. Earth Syst. Sci. 20:1373-1385. doi:10.5194/hess-20-1373-2016

Rivera Villarreyes, C.A., G. Baroni, and S.E. Oswald. 2011. Integral quantification of seasonal soil moisture changes in farmland by cosmic-ray neutrons. Hydrol. Earth Syst. Sci. 15:3843-3859. doi:10.5194/hess-15-3843-2011

Rosolem, R., T. Hoar, A. Arellano, J.L. Anderson, W.J. Shuttleworth, X. Zeng, and T.E. Franz. 2014. Translating aboveground cosmic-ray neutron intensity to high-frequency soil moisture profiles at sub-kilometer scale. Hydrol. Earth Syst. Sci. 18:4363-4379. doi:10.5194/hess-18-4363-2014

Rosolem, R., W.J. Shuttleworth, M. Zreda, T.E. Franz, X. Zeng, and S.A. Kurc. 2013. The effect of atmospheric water vapor on neutron count in the cosmic-ray soil moisture observing system. J. Hydrometeorol. 14:16591671. doi:10.1175/JHM-D-12-0120.1
Schattan, P., G. Baroni, S.E. Oswald, J. Schober, C. Fey, C. Kormann, et al. 2017. Continuous monitoring of snowpack dynamics in alpine terrain by aboveground neutron sensing. Water Resour. Res. 53:3615-3634. doi:10.1002/2016WR020234

Schreiner-McGraw, A.P., E.R. Vivoni, G. Mascaro, and T.E. Franz. 2016. Closing the water balance with cosmic-ray soil moisture measurements and assessing their relation to evapotranspiration in two semiarid watersheds. Hydrol. Earth Syst. Sci. 20:329-345. doi:10.5194/hess-20-329-2016

Schrön, M., M. Köhli, L. Scheiffele, J. Iwema, H.R. Bogena, L. Lv, et al. 2017. Improving calibration and validation of cosmic-ray neutron sensors in the light of spatial sensitivity: Theory and evidence. Hydrol. Earth Syst. Sci. Discuss. doi:10.5194/hess-2017-148

Sigouin, M.J.P., and B.C. Si. 2016. Calibration of a non-invasive cosmicray probe for wide area snow water equivalent measurement. Cryosphere 10:1181-1190. doi:10.5194/tc-10-1181-2016

Simpson, J.A. 1951. Neutrons produced in the atmosphere by the cosmic radiations. Phys. Rev. 83:1175-1188. doi:10.1103/PhysRev.83.1175

Shuttleworth, J., R. Rosolem, M. Zreda, and T. Franz. 2013. The COsmic-ray Soil Moisture Interaction Code (COSMIC) for use in data assimilation. Hydrol. Earth Syst. Sci. 17:3205-3217. doi:10.5194/hess-17-3205-2013

Smart, D.F., and M.A. Shea. 2001. Geomagnetic cutoff rigidity computer program: Theory, software description and example. NAG5-8009. Univ. of Alabama, Huntsville.

Tian, Z., Z. Li, G. Liu, B. Li, and T. Ren. 2016. Soil water content determination with cosmic-ray neutron sensor: Correcting aboveground hydrogen effects with thermal/fast neutron ratio. J. Hydrol. 540:923-933. doi:10.1016/j.jhydrol.2016.07.004

Vereecken, H., J.A. Huisman, H. Bogena, J. Vanderborght, J.A. Vrugt, and J.W. Hopmans. 2008. On the value of soil moisture measurements in vadose zone hydrology: A review. Water Resour. Res. 44(4):W00D06. doi:10.1029/2008WR006829

Vinodkumar, I. Dharssi, J. Bally, P. Steinle, D. Mc Jannet, and J. Walker. 2017. Comparison of soil wetness from multiple models over Australia with observations. Water Resour. Res. 53:633-646. doi:10.1002/2015WR017738

Zhu, X., M.A. Shao, C. Zeng, X. Jia, L. Huang, Y. Zhang, and J. Zhu. 2016. Application of cosmic-ray neutron sensing to monitor soil water content in an alpine meadow ecosystem on the northern Tibetan Plateau. J. Hydrol. 536:247-254. doi:10.1016/j.jhydrol.2016.02.038

Zhu, Z., L. Tan, S. Gao, and Q. Jiao. 2015. Observation on soil moisture of irrigation cropland by cosmic-ray probe. IEEE Geosci. Remote Sens. Lett. 12:472-476. doi:10.1109/LGRS.2014.2346784

Zreda, M. 2016. Land-surface hydrology with cosmic-ray neutrons: Principles and applications. J. Jpn. Soc. Soil Phys. 132:25-30.

Zreda, M., D. Desilets, T.P.A. Ferré, and R.L. Scott. 2008. Measuring soil moisture content non-invasively at intermediate spatial scale using cosmicray neutrons. Geophys. Res. Lett. 35:L21 402. doi:10.1029/2008GL035655

Zreda, M., W.J. Shuttleworth, X. Zeng, C. Zweck, D. Desilets, T. Franz, and R. Rosolem. 2012. COSMOS: The COsmic-ray Soil Moisture Observing System. Hydrol. Earth Syst. Sci. 16:4079-4099. doi:10.5194/hess-16-4079-2012

Zweck, C., M. Zreda, and D. Desilets. 2013. Snow shielding factors for cosmogenic nuclide dating inferred from Monte Carlo neutron transport simulations. Earth Planet. Sci. Lett. 379:64-71. doi:10.1016/j.epsl.2013.07.023 